This item was submitted to Loughborough's Research Repository by the author.

Items in Figshare are protected by copyright, with all rights reserved, unless otherwise indicated.

\title{
Valuation of aircraft noise by time of day: a comparison of two approaches
}

PLEASE CITE THE PUBLISHED VERSION

PUBLISHER

(C) Taylor \& Francis

LICENCE

CC BY-NC-ND 4.0

\section{REPOSITORY RECORD}

Bristow, Abigail L., and Mark Wardman. 2019. "Valuation of Aircraft Noise by Time of Day: A Comparison of Two Approaches". figshare. https://hdl.handle.net/2134/2786. 
This item was submitted to Loughborough's Institutional Repository by the author and is made available under the following Creative Commons Licence conditions.

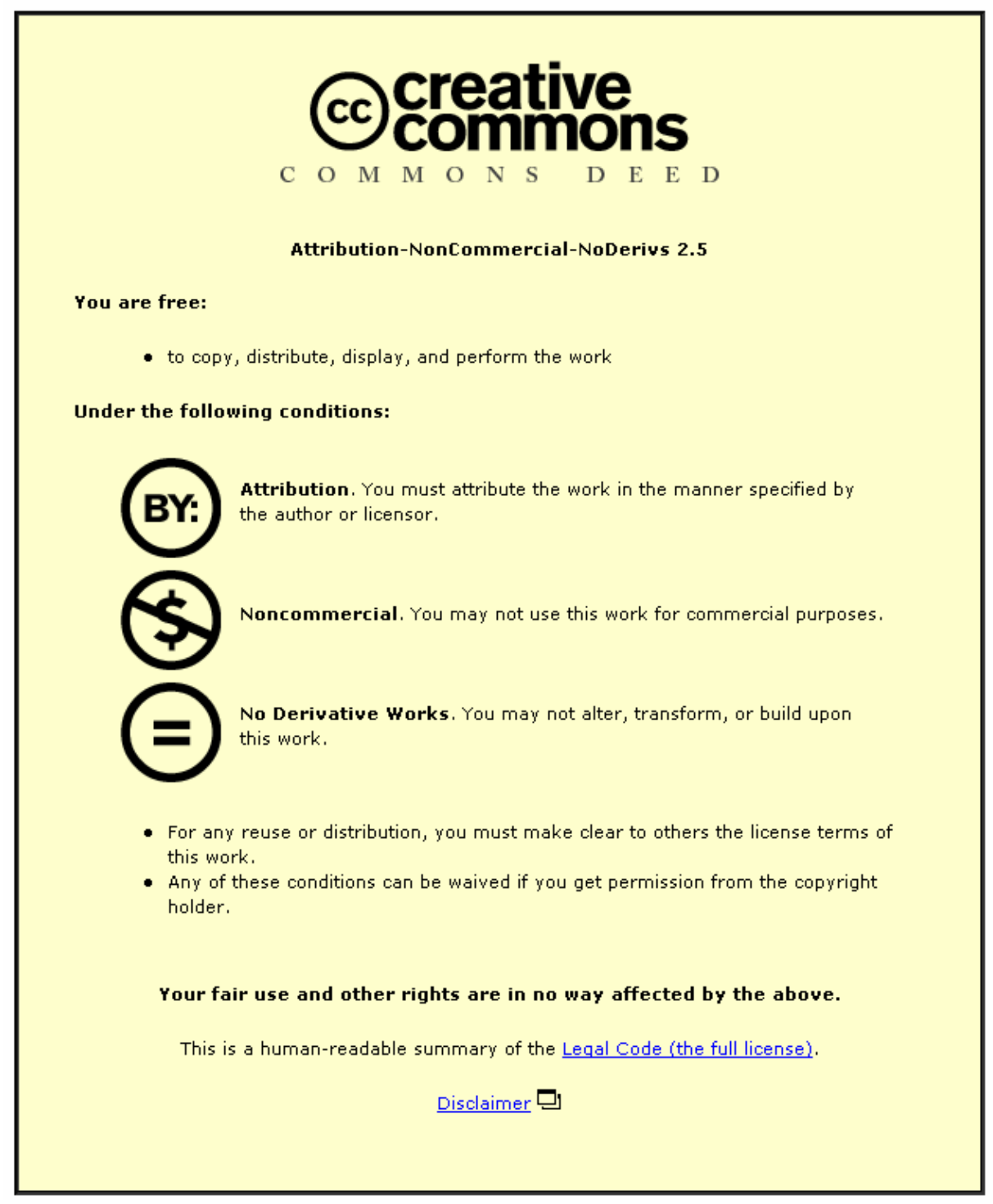

For the full text of this licence, please go to: http://creativecommons.org/licenses/by-nc-nd/2.5/ 
Bristow A.L and Wardman M. (2006) Valuation of Aircraft Noise by Time of Day: A Comparison of Two Approaches. Transport Reviews. 26(4) pp417- 433

\title{
VALUATION OF AIRCRAFT NOISE BY TIME OF DAY: A COMPARISON OF TWO APPROACHES
}

\author{
Abigail L. Bristow \\ Transport Studies Group, Department of Civil and Building Engineering, \\ Loughborough University \\ a.l.bristow@lboro.ac.uk, 01509223781 \\ Mark Wardman \\ Institute for Transport Studies, University of Leeds \\ mwardman@its.leeds.ac.uk, 01133435349
}

\begin{abstract}
This paper reports an innovative application of stated preference techniques to derive values of aircraft noise by time of day and day of week. Revealed preference techniques cannot provide such segmentations which would clearly be of use in policy development especially relating to airport operations. Given the lack of research on this issue the work reported here is highly experimental. Two stated preference experiments were designed. The first focussed on a single time period whilst the second asked respondents to trade between time periods. Both approaches yielded results that are plausible and mutually consistent in terms of relative values by time period. We conclude that stated preference techniques are particularly useful in this context where the use of aggregated values may lead to non-optimal policy decisions.
\end{abstract}




\section{Introduction}

Aircraft noise is a major source of annoyance near airports and the number of aircraft movements around airports has been growing strongly and will continue to do so. Identifying the monetary values people place on aircraft noise is important in informing policy decisions relating to investment, mitigation and compensation. Traditional hedonic pricing methods provide few insights into many of the key factors that influence annoyance and valuation, such as variations according to socioeconomic characteristics, time of day or day of week, and individual preferences. In this paper we report a novel application of stated preference (SP) techniques to the valuation of aircraft noise by time of day and day of week. ${ }^{1}$

It is important to establish whether the values households place on noise disturbance vary by time of day because if they do then policies based on values which do not make this distinction may not be optimal. We would expect residents' values of noise as experienced at home to vary by time of day and day of week for a variety of reasons:

- Different activities undertaken at different times of day will vary in their susceptibility to interference from aircraft noise;

- Time spent in the home varies both across individuals and time periods, and those who have greater exposure to noise will, other things equal, have higher valuations;

- Aircraft movements vary by time of day and day of week and, other things equal, values would be expected to be higher in periods when movements and hence noise levels are higher.

An important additional consideration is that, even if valuations were the same across time periods, it may be necessary to offer different SP exercises by time period simply to customise the design for realism purposes given that aircraft movements vary by time of day.

Existing evidence that noise is more annoying in the evenings and at night has now been embodied in the use of weighted noise indices such as Ldn (day-night and Lden $^{2}$ (day-evening-night) (European Parliament and Council, 2002a; Miedema and Oudshoorn, 2001), and improved knowledge on variations in the costs of noise by time of day would assist in the management of noise at airports. This research is timely because Directive 2002/30/EC (European Parliament and Council 2002b) requires authorities to assess the costs and benefits of noise management measures and considers the use of economic incentives, whilst the UK Government's "The Future of Air Transport" White Paper (Department for Transport, 2003) acknowledges the problem of night time noise and suggests greater use of differential landing charges according to noise levels.

At the outset of this research, we were aware of only a few studies that had applied the contingent valuation method (CVM) to the valuation of aircraft noise (Pommerehne 1988; Fietelson et al., 1996; Navrud 2000 and Faburel and Luchini 2000) and only one study applying SP (Thune-Larsen, 1995). None of these studies addressed the issue of variations in values of aircraft noise by time period. Indeed,

\footnotetext{
${ }^{1}$ This study was undertaken as part of the $5 \mathrm{~A}$ project (Attitudes to Aircraft Annoyance Around Airports) funded by EUROCONTROL, the European organisation with responsibility for air traffic control.

${ }^{2}$ Where the average sound level is measured for different time periods and the evening and night time periods are then weighted by $+5 \mathrm{~dB}(\mathrm{~A})$ and $+10 \mathrm{~dB}(\mathrm{~A})$ respectively.
} 
even in the context of road traffic noise where more studies have been undertaken we are not aware of any that that have segmented by time period with the exception of the CVM study of road traffic noise by Barreiro et al (2000) which used a day night segmentation only..

Two studies have since applied SP techniques to examine variations in aircraft noise values by time of day. Comparison with the results obtained by Carlsonn et al., (2004) is not straightforward given the different approach adopted whilst ongoing research commissioned by the UK Department for Transport is not in the public domain.

The approach used here was therefore highly experimental. Two related SP experiments were designed. One was based upon residents' evaluations of aircraft movements by type of aircraft within a specified time period. The other required aircraft movements across different time periods to be traded-off.

The time periods used were chosen to reflect the differences in movements by time period at the airports concerned, the expected differences in time spent at home and hence exposure to aircraft noise, and variations in the types of activity undertaken at home. The time periods used throughout this study were: weekdays 6-9am; weekdays 9am-6pm; weekdays 6-10pm; Saturday 6-9am; Saturday 9am-6pm; Saturday 6-10pm; Sunday 9am-6pm; and every night 10pm-6am.

There are two purposes to which we can put valuations split by time period. The first, termed the decompositional approach, is to use the values to disaggregate an overall value, such as might be provided by hedonic pricing, into period specific values. This procedure requires that the disaggregate values are unbiased in relation to each other. The other purpose, termed the compositional approach, obtains the overall valuation as the sum of the values estimated for each time period. This additionally requires that the absolute period specific values are unbiased and can be summed to obtain the overall value. This research was primarily of a decompositional nature, assessing the extent to which two different SP approaches can provide similar relative values by time period. Nonetheless, we also compare the extent to which the two SP approaches provide similar overall values when the disaggregate values are summed across time periods.

\section{Design and Implementation of the Stated Preference Experiments}

\subsection{The Airports}

Surveys were conducted around three airports since one of the aims of the study was to evaluate cultural and socio-economic variations in attitudes towards and valuations of aircraft annoyance.

Manchester Airport was selected as representative of a large regional airport exhibiting significant growth over time. Lyon has some similarities with Manchester as a large regional airport but is set in a much more rural environment. The populations around these two airports are broadly comparable in terms of income levels. Bucharest Airport was selected as an airport with a much smaller number of aircraft movements and significantly lower income levels amongst the local population. A second runway opened at Manchester in 2001. Whilst the controversy has now largely died down, one adversely affected area is included in our study. Proposals to build two new runways at Lyon have been approved and there is an active opposition group. Bucharest has seen no significant changes since 1997 when 
the new international terminal opened. However, there might be much more tolerance of increased aircraft activity in a low income country such as Romania given low existing movements and the perceived associated economic development benefits.

Table 1 shows the aircraft movements by time period at each airport. Note that these are half the total movements and thus represent the number of movements any one household might be exposed to in order to reflect households' experiences of aircraft as accurately as possible.

\section{Insert table 1 about here}

Manchester is clearly the busiest of the three airports, with an early morning peak in movements but high levels throughout the day. Lyon has fewer overall movements but has a strong weekday evening peak at which time it is as busy as Manchester. Bucharest has a small number of flights with no peaking. The variation shown in table 1 clearly illustrates the need for experimental designs to be customised by time period.

The survey contained a range of questions on socio-economic factors and attitudes to noise and levels of disturbance alongside the SP experiments. Respondents were recruited from a number of locations around each airport which were selected to give a range of exposure to aircraft noise and socio-demographic characteristics. Quotas were set for age group, gender and employment status to ensure a reasonable spread. A small payment was made to those participating. The interviews were conducted in late $2002^{3}$ with groups of up to 20 respondents at a time at a suitable local venue. This approach is not only cost effective but also meant that survey staff could explain each section and assist as required. The total sample size was 647, with a minimum of 200 respondents at each airport. Full details of the survey design, locations and implementation may be found in Bristow and Wardman (2003).

\subsection{The Stated Preference Experiments}

This study was exploratory in nature. It therefore evaluated two different approaches to the valuation of aircraft movements and noise disaggregated by time period. The significant problem faced in seeking to represent noise to respondents in hypothetical surveys has been addressed elsewhere in this study (Bristow and Wardman 2004), building upon the authors' previous noise valuation research (Arsenio et al., 2000; Wardman and Bristow, 2004). Aircraft movements were used in both SP exercises as an easily understood proxy for aircraft noise. In this context, the most appropriate numeraire is the local tax since it is the monetary instrument most likely to be perceived as in any way linked to environmental attributes. Local tax is a household level payment and we therefore assume that the respondent (who may not personally pay the tax) gives a value for the household as a whole ${ }^{4}$.

\subsubsection{Within Period Stated Preference Exercise}

\footnotetext{
${ }^{3}$ The stated preference experiments were based on the summer schedules (shown in table 1 and this was clearly specified in the questionnaire.

${ }^{4}$ We recognise that this assumption could be challenged equally the assumption that a respondent would give an individual willingness to pay in terms of a household level payment would also be open to challenge. This issue is of greatest importance with respect to absolute values rather than the relative values which are the primary focus of this paper. We return to this point in the conclusions.
} 
The most straightforward approach is to require respondents to trade-off different levels of aircraft movement against money within a given time period. This is termed the within period (WP) exercise. By offering different time periods to different respondents, a picture of how valuations vary by time period can be built up.

The WP exercise is depicted in table 2. It can be viewed as a standard SP approach, involving the choice between two options each characterized by a limited number of attributes that we wish to value and a numeraire. In the exercise adopted in this study, each option distinguished between three types of aircraft movement on the grounds that the response to variations in movements would to some extent depend on the type of aircraft involved. These options were to be evaluated in the context of one of the specific time periods set out in the introduction. Movements in other time periods were specified to be as now.

A standard fractional factorial design procedure was used to combine the levels of the attributes in each scenario to be evaluated. The full number of scenarios produced by the design was sixteen, but any individual was presented only with eight of them. Simulation tests were undertaken on the designs using synthetic data to ensure that they were satisfactory from a statistical perspective. This led to a number of modifications to increase the precision of the parameter estimates.

\section{Insert table 2 about here}

A potentially serious shortcomings of this approach is that there may be an unaccounted for package effect (Jones, 1997) or what the environmental literature terms part-whole bias. There are a number of possible reasons why an overall value is not simply the sum of relevant disaggregated values. Firstly, interactions between or non-linearities across time periods mean that we cannot simply sum the valuations obtained by time period. Secondly, halo effects could be present, whereby changes in other time periods are implicitly assumed or perceived to co-exist alongside those in the time period in question. Thirdly, budget effects may limit the amount of money a household is prepared to spend on improvements in aircraft noise, and thus again it would not be valid to sum across independently obtained time period specific values. Quite separate from a package effect, there could be a feeling that respondents are less likely to provide accurate accounts of the relative valuations by time period when only a specific period is considered and there is no comparison across time periods.

As a result of a package effect, the absolute values obtained by time period from the WP exercise cannot be summed to obtain an overall value. However, the relative values by time period may also be biased. Whilst it is a common assumption that the disaggregated values are unbiased in relation to each other, and each simply needs to be rescaled by a common factor to allow for the package effect, we are only aware of one study (MVA, 1993) that has provided any empirical justification for this approach.

\subsubsection{Between Period Stated Preference Exercise}

An alternative approach involves the simultaneous consideration of different time periods and trading-off variations in aircraft noise across these different time periods. This is termed the between period (BP) exercise. This does not make the WP approach redundant since the latter is needed to examine other factors, such as type of aircraft, which could not feasibly be evaluated alongside different time periods in the same exercise. 
The purpose of the BP exercise is to obtain valuations for the whole range of time periods simultaneously. The main drawback of covering such a range of attributes within a conventional pairwise SP approach is that of task complexity. There is evidence to indicate that task complexity can influence valuations, largely through the use of simplifying but inappropriate choice rules or ignoring attributes (Malhotra, 1982; Johnson and Meyer, 1984; Timmermans, 1993; Widlert, 1998; Arentze et al., 2003). Following the pattern of the WP exercise set out in table 2, each time period would be a separate variable. Given the time periods of interest here, the BP exercise would take the form illustrated in table 3.

This exercise would involve the simultaneous consideration of 18 pieces of information. If each variable differs between options $A$ and $B$ this is an enormous amount of information to process in arriving at a choice. Even where some variables are the same for options $A$ and $B$ the respondent is still required to identify this prior to discounting them. Even with fewer than the 8 time periods that we here have, the task would remain daunting, particularly in an artificial market covering attributes that are not routinely evaluated by households.

\section{Insert table 3 about here}

The challenge therefore is to be able to cover a wide range of variables which retains the simultaneous consideration of different time periods yet ensures that the task is manageable. The means by which this has been tackled has been to use an approach which involves the evaluation of a range of attribute specific variations one at a time rather than the conventional procedure of multiple trade-offs.

Our view is that if offered a whole series of improvements (deteriorations) to specific attributes, such as changes to aircraft movements in each of eight time periods, respondents can more readily state which attribute variation they would most like to achieve (avoid) than they can weigh up the net benefit of differences in each of the eight time periods between two alternatives.

Respondents were informed of the current situation. In the case of Manchester, this is the central column in table 4. A number of improvements to the current situation are specified, depicted in the columns to the right of the current situation. Similarly, a number of deteriorations to the current situation are set out. The respondent is first asked to consider all the improvements and to select that which they would most like. Initially this involves evaluating the nine possible improvements in the right hand column of Table 4. Once this preferred improvement is identified, the respondent is told that it is no longer available and to identify which improvement is preferred from those remaining. The process is continued until all the one-dimensional scenarios have been evaluated and a ranking of the full set of improvements achieved. The respondent is then asked to complete a similar exercise for the deteriorations, working through from the worst deterioration to that least disliked.

In summary we believe the task represented in Table 4 is much simpler than that in Table 3 because it is possible to complete the ranking simply by comparing variation in two attributes at a time whilst the approach in Table 3 requires the simultaneous consideration of variation in 9 attributes. However this simplicity is achieved at the cost of a more tedious task; evaluating the improvements in Table 4 would involve 25 rankings.

In order to increase the variation in the monetary variable with a view to obtaining more precise cost coefficient estimates, two sets of tax variation were used, with respondents randomly allocated one of them. 
The approach has similarities with the priority evaluator technique which has been used when there has been a need to evaluate a large number of variables, such as the many different types of rolling stock and station facility attributes (MVA, 1985; 1986) and diverse quality of life issues (Hoinville, 1971; Brown, 1996). It will be noted that the BP exercise deals only with improvements or with deteriorations. The traditional priority evaluator method allows improvements in one attribute to be purchased at the cost of a deterioration in another attribute rather than at the cost of foregoing some other improvement. This is the same as allocating a set of points to the current situation and, after assigning 'points prices' to other levels of the attributes, requiring the respondent to allocate the 'points budget' across attributes to identify the best combination. The latter is modelled as preferred to all other possible achievable combinations. However, this builds in linear dependency such that the undoubted information content cannot be extracted from the data.

\section{Results}

The ALOGIT (Hague Consulting Group, 2000) package was used to estimate the relative importance attached to each attribute in each exercise and its jack-knife procedure accounted for individuals' multiple but not independent choices. The ordered logit model (Chapman and Staelin, 1982) was used to analyse the BP data whilst the WP data was analysed using a standard logit model.

In all the models reported, the cost coefficient is expressed in $€$ per week. The aircraft coefficients represent the number of movements experienced per hour in the time period in question. Thus the valuations represent how much a household is prepared to pay to remove an aircraft in each hour in the relevant time period.

\subsection{Within Period SP Results}

The results for the WP models are reported in table $5^{5}$. The samples of 200, 210 and 237 respondents in Manchester, Lyon, and Bucharest yielded 1545, 1647 and 1895 SP choices respectively. The proportion of choices favouring the dearer but quieter option were 50\% in Manchester, 80\% in Lyon and 31\% in Bucharest.

Sample sizes per time period are around 25 individuals, so it is not surprising that for some time periods it was not possible to recover coefficients that were anywhere near to being significant and these variables were removed from the model entirely. Although the $\rho^{2}$ goodness of fit measures, specified with respect to constants, are low, contrasting with values of 0.10 and more which are typical in more conventional choice contexts, this is not a choice context with which respondents will be routinely familiar.

There was no preference for one alternative over the other, all else equal, in the Manchester model. In the case of Lyon, however, there was a strong preference equivalent to around €25 per week in favour of the quieter but dearer alternative. Not only does this provide a better fit, but the cost coefficient was actually wrong sign in the absence of the constant term. Focus groups conducted prior to the SP exercises (Heaver, 2002) indicated that the Lyon sample was highly sensitive to aircraft noise

\footnotetext{
${ }^{5}$ These results differ slightly from those previously reported in Bristow and Wardman (2003) which contained an error in the process of correcting for repeated observations.
} 
and that responses to an SP exercise might be influenced by protests against the planned airport expansion. The constant term is presumably discerning this. On the other hand, the Bucharest model exhibits a significant constant in favour of the noisier but busier alternative, and in the absence of this constant the aircraft variables tend to have wrong sign coefficients. We speculate that this is a preference for the broader economic benefits associated with airport expansion. This tolerance of aircraft movements due to the perceived positive economic impacts in what is a poor local economy emerged in the focus groups.

\section{Insert table 5 about here}

In Manchester, aircraft movements in the early morning had a far from significant value. This is not to say that they have a zero value but that they would appear to be lower than for the other time periods. The small time period will have contributed to this result but there will be some who are asleep in this period and others will be busying themselves preparing for the day's activities. The value for every weekday during the day is less than the same time period for Saturday alone. This is presumably because few are at home during the day on a weekday but are on a Saturday. They might also be undertaking activities which involve being outside which are more likely to be affected by aircraft noise. Surprisingly there was no significant effect apparent for Saturday evening but Sunday has a relatively high value which is to be expected given the length of the time period and the expected high level of exposure. Not surprisingly, night flights are valued highly.

In Lyon, at least reasonably significant coefficient estimates were obtained for all but one time period. As expected from the focus groups, aircraft movements in the evening have a high value, with that for weekdays being higher than for Saturdays given the longer time period. This is linked to the evening outdoor activities common amongst these households. The low value for Sunday is surprising, given the length of the period and that people are more likely to be at home, and this is so despite it being one of the more precisely estimated coefficients. Night flights have a relatively high value as expected

Significant effects were apparent for all but two Saturday time periods in Bucharest. A feature of the results is that there is little difference in the values by time period, with night values notably being little different. To some extent, different levels of exposure could compensate for the different lengths of time period, so that the values for weekdays between 9am and 6pm are the same as for the two adjacent periods. The short time period for Saturday can explain the lack of any effect for two of its time periods although the early morning has noticeably highly valued aircraft movements. In part, this pattern of results might be a function of Bucharest respondents having a greater difficulty answering the questions, which is in line with the lower $\rho^{2}$ goodness of fit for this sample and the impressions gained from observing the interviews.

As far as the absolute values are concerned, they do generally appear on the high side. We have addressed this issue elsewhere (Bristow and Wardman, 2004) and will return to it below. Nonetheless, the relative values do have a reasonableness about them whilst it is encouraging that the Manchester and Lyon values are reasonably similar given similar income levels and that the Bucharest residents who have lower incomes are more sensitive to cost variations. In addition to time of day effects, we were also able to discern variations according to income groups and, to some extent, according to type of aircraft (Bristow and Wardman, 2003).

\subsection{Between Period SP Results}


The BP exercise also gives results by time of day and day of week, but in this case as a result of trading between time periods. In order to avoid overloading respondents, it was intended that the BP exercise was to be undertaken only by those who had completed the rest of the questionnaire somewhat ahead of others. In the event, all respondents in the Bucharest survey completed this exercise. Separate models are estimated for improvements to and deteriorations of the current situation and the results are presented in table 6 . The models achieve respectable goodness of fits and almost all of the estimated coefficients are significant at the usual $5 \%$ level.

Some respondents ranked 'lexicographically' on one attribute at a time. Although such response orderings could reflect actual preferences, they might also stem from strategic bias or from some response simplifying process. In Manchester there were no such orderings for improvements whilst $2 \%$ responded in this manner for deteriorations. The corresponding figures for Lyon were $6 \%$ and $20 \%$ and for Bucharest were $1 \%$ and $5 \%$. Given the generally low proportion of such responses and that they could reflect a true pattern of preferences, these respondents have been retained.

In addition, we can identify those who failed to rank the alternatives in logical order, such as preferring, say, a $£ 3$ per week tax saving to a $£ 5$ per week tax saving. This reduces the Manchester data set for improvements and deteriorations by $22 \%$ and $70 \%$ respectively, with corresponding figures of $14 \%$ and $32 \%$ for Lyon and an alarming $82 \%$ and $62 \%$ for Bucharest. The Bucharest survey team reported that respondents had problems in completing the BP exercise, but this was not identified as an issue in Lyon or Manchester. Whilst we have estimated models which remove the illogical respondents, it does not materially alter the conclusions that can be drawn from this work. Given the relatively small samples involved, and that we have not removed any such responses from the WP data set since they are not as readily identified, we on balance prefer the BP models which do not remove any of these individuals.

\section{Insert table 6 about here}

The Manchester improvements model indicates that values are higher when respondents are more likely to be at home. The evening values are relatively high as are the values for Saturdays and Sundays, particularly when the time period is borne in mind, and night values are disliked. The same can be said about the deteriorations model but with a more pronounced value for night flights.

The pattern of valuations in both Lyon models is for high values at the weekends, particularly given the time periods involved, reflecting different exposure levels. Night time flights are disliked, particularly for deteriorations.

The pattern of results differs somewhat between the two Bucharest models. As with the WP model, there is little differentiation between time periods in the deteriorations model other than the relatively high value for night flights. There is, however, much more discrimination in the improvements model with evening and night flights relatively highly valued.

The values of improvements are consistently and considerably larger than the values obtained from the deteriorations model at all three locations. This pattern of values could reflect a protest against higher taxes but a general lack of belief that lower taxes would ever materialise. The difference between the two is particularly 
pronounced in Bucharest and this could be because additional aircraft movements are associated with airport expansion and the economic benefits this brings.

The values vary in relation to each other in a generally not unreasonable manner and seem to contain useful information. For example, variations in the number of aircraft at night are invariably valued more highly, as expected, than variations in daytime flights. It is the weekday evening period where the values tend to be highest whilst Saturday has values as high or higher than weekdays even though it forms a lower proportion of time since people are then more likely to be at home. However, the absolute values seem too large, particularly those based on improvements and especially for the residents of Lyon.

\subsection{Variation by Time Period: Comparison of Methods}

Table 7 indicates the extent to which the WP and BP exercises provide similar values by time period. Given that the WP models could not provide robust results for all periods, we have compared across those periods for which coefficients are reported for the WP models in table 5. The figures in table 7 represent the proportions that each value in a period forms of the sum of values across all relevant periods. Separate figures are provided for the improvements and deteriorations BP models as well as the average of the two.

\section{Insert table 7 about here}

There is a very high degree of similarity between the relative valuations by time period for Manchester, especially for the average of the two BP results which has a correlation of 0.94 with the WP proportions. The figures for improvements and deteriorations are also here closely associated, with a correlation of 0.87 .

There is not the same high level of correspondence for Lyon. Although the correlation between the proportions from the improvements and deteriorations BP models is high at 0.82 , it is much lower although still correct sign at 0.38 between the WP and mean BP figures. The key differences are in two of the seven periods, with the WP model implying a much lesser importance of night time noise but a particularly high significance to weekday evening noise.

For Bucharest, the association between the figures of the different methods are correct sign but modest. The correlation between the improvements and deteriorations proportions in the BP model is 0.54 , falling to 0.43 between the mean BP figures and the WP results. The latter is adversely affected by the difference between the figures for night time for the two models.

Although the results are mixed, with those for Manchester extremely good, the relatively low level of precision with which WP coefficients were estimated, as a result of spreading each airport's sample of around 200 across eight time periods, and the small BP samples for Manchester and Lyon, will have had an influence here. Bearing this in mind, and that the correlations between the BP and WP models are always positive, we conclude that there is an encouraging degree of correspondence between the two approaches and that respondents can distinguish between the aircraft annoyance of different time periods without having to consider all time periods simultaneously. The only other study that has reported values by time of day (Carlsson et al., 2004) finds more ambiguous results.

Finally, we examine the overall valuations implied by the BP and WP models. These are reported in table 8 . For both Manchester and Bucharest the BP improvement 
value exceeds the WP value which in turn exceeds the BP deterioration value, and the mean BP value is similar to the WP value. However, this pattern is clearly not present in the Lyon results. Regardless of the similarities between the compositional values for WP and BP for two of our three locations, we would not advocate the use of these methods to obtain overall values simply because the values are implausibly large. Not only do they appear too large, but we have provided evidence elsewhere that strongly suggests that they are too large (Bristow and Wardman, 2004). A method not unlike the BP approach was used to conceal the purpose of the exercise by offering variations in daytime and evening aircraft movement alongside a whole range of other local quality of life variables. These related to crime, air quality, school quality, road traffic levels, condition of local roads and pavements, street cleanliness, shopping, health and leisure facilities, and council tax. The overall values based on improvements and deteriorations were $€ 1.49$ and $€ 0.81$ for Manchester, $€ 2.22$ and $€ 2.48$ for Lyon, and €0.48 and €0.03 for Bucharest. Not only are these values considerably exceeded by the overall BP and WP figures, there are instances where they are exceeded by a period specific WP or BP value.

Insert table 8 about here

\section{CONCLUSIONS}

This paper has reported research that developed and applied innovative Stated Preference (SP) experiments to derive values of aircraft noise disaggregated by time of day and day of week. We are aware of only one study that has previously reported such analysis. The findings reveal that valuations do vary by time period and in a generally plausible manner.

One SP experiment focused on aircraft movement in a specific time period, with movements in other periods specified to be constant. Different time periods were evaluated by different respondents so that a picture of variations in valuations by time period could be built up. The other SP exercise explicitly addressed aircraft movements across eight different time periods. Although the two SP experiments used were very different in nature, they yield similar sensible patterns of relative values by time period. This is an encouraging finding. We conclude that either approach could be used to determine disaggregate values, with a preference for the approach based on a single time period since it is simpler and permits the consideration of other factors, such as aircraft type, irregular patterns of departures within a time period, or the evaluation of aircraft annoyance in the context of different activity patterns at home.

On the other hand, however, these methods should not be used to determine overall values since they would clearly be too high. We have argued and demonstrated elsewhere (Bristow and Wardman 2004) that absolute values should be derived from a 'higher level' SP experiment where the purpose of the survey is masked to avoid strategically biased responses. Clearly, it is not possible to mask the purpose of an exercise which focuses on aircraft movements by time period. Alternatively, the hedonic pricing approach might be used to deliver a top level valuation. These overall values can then be decomposed using the methods outlined in this paper, but the compositional approach is not recommended.

This study was experimental in nature and further work is clearly required to: refine the techniques; explore the consistency of such values in different airports and countries; link values to objective measures of noise; and consider the best source of overall values. Further research is required into the possible existence of interactions 
across time periods and non-linearities, the extent to which the length of time period influences responses and links with exposure levels, activity patterns and attitudes towards annoyance. There is also a need to explore the extent to which any differences in response to the WP and BP experiments is due to the differences in the nature of the task. Whilst we feel that our between period method, seems to be an attractive solution to the problems of task complexity when many attributes are involved, this requires further empirical verification. The method also needs to be developed to allow the simultaneous consideration of both improvements and deteriorations in attributes.

Finally, and with regard to the absolute values obtained, there is a need to examine dynamic household decision making in more detail to distinguish between individual valuations, which are a feature of much consumer decision making, and household valuations, which have more relevance when household impacts, such as noise, are concerned and the payment mechanism, such as local tax, impacts at the household level.

\section{Acknowledgements}

This study was funded by the EUROCONTROL Experimental Centre and we would like to thank Ted Elliff, Peter Hullah and Elisabeth Plachinski for their support throughout the project. The views expressed in the paper are those of the authors alone.

\section{References}

Arentze, T., Borgers, A., Timmermans, H. and DelMistro, R. (2003) Transport Stated Choice Responses: Effects of Task Complexity, Presentation Format and Literacy. Transportation Research E 39 229-244.

Arsenio E., Bristow A.L., and Wardman M. (2000) An innovative stated preference computer survey model for valuing noise impacts from road traffic. Proceedings of Seminar F (Behavioural Modeling) of the European Transport Conference

Barreiro J., Sanchez M. and Viladrich-Grau (2000) How much people are willing to pay for silence? A one and one half bound DC CV estimate. Internoise 2000 The $29^{\text {th }}$ International Congress and Exhibition on Noise Control Engineering, 27-30 August 200, Nice, France.

Bristow A.L. and Wardman M. (2004) Using Stated Preference to Value Annoyance from Aircraft: A Comparison of Approaches, paper to envecon 2004 Applied Environmental Economics Conference $26^{\text {th }}$ March 2004 Royal Society London http://www.eftec.co.uk/TESTING\%20-\%20Bristow\%20and\%20Wardman.pdf

Bristow A.L., Wardman M. (2003) Attitudes Towards and Values of Aircraft Annoyance and Noise Nuisance. Attitudes to Aircraft Annoyance Around Airports (5A) Survey Report. EEC/SEE/2003/002. EUROCONTROL Experimental Centre, France.

http://www.eurocontrol.int/eec/public/standard page/SEE 2003 report 2.html

Brown, N (1996) Quality of Life Issues within an Integrated Transport Strategy Framework. PhD Thesis, University of Leeds. 
Carlsson F., Lampi E. and Martinson P. (2004) The marginal values of noise disturbance from air traffic: does the time of day matter? Transportation Research $D$ 9 373-385.

Chapman, R.G. and Staelin, R. (1982) Exploiting Rank-Ordered Choice Set Data Within the Stochastic Utility Model. Journal of Marketing Research 19 288-301

Department for Transport (2003) The Future of Air Transport. Cm6046

European Parliament and Council (2002a) Relating to the assessment and management of environmental noise. Directive 2002/49/EC

European Parliament and Council (2002b) On the establishment of rules and procedures with regard to the introduction of noise-related operating restrictions at Community Airports. Directive 2002/30/EC

Faburel G. and Luchini S. (2000) The social cost of aircraft noise: the contingent valuation methods applied to Paris-Orly Airport. . Internoise 2000 The $29^{\text {th }}$ International Congress and Exhibition on Noise Control Engineering, 27-30 August 200, Nice, France.

Fietelson E.I., Hurd R.E. and Mudge R.R. (1996) The impact of airport noise on willingness to pay for residences. Transportation Research D 1 1-14.

Hague Consulting Group (2000) ALOGIT 4.0EC. The Hague.

Heaver C. (2002) Attitudes to Aircraft Annoyance around Airports (5A) Focus Group Report. EEC/ENV/2002/09

http://www.eurocontrol.int/eec/public/standard page/SEE 2002 report 9.html

Hoinville, G. (1971) Evaluating Community Preferences. Environment and Planning 3 33-50.

Johnson, E.J. and Meyer, R.J. (1984) Compensatory Choice Models of Noncompensatory Processes: The Effect of Varying Context. Journal of Consumer Research 11 45-57.

Jones, P. (1997) Addressing the 'packaging' problem in stated preference studies. Proceedings of Seminar D, PTRC European Transport Forum, London.

Malhotra, N.K. (1982) Structural Reliability and Stability of Nonmetric Conjoint Analysis. Journal of Marketing Research 19 199-207.

Miedema H.M.E and Oudshoorn C.G.M (2001) Annoyance from Transportation Noise: Relationships with Noise Exposure Metrics DNL and DENL and Their Confidence Intervals. Environmental Health Perspectives 109(4) 409-416.

MVA (1993) Passenger Priorities Research Stage 1. Prepared for London Underground Limited.

MVA (1986) Evaluation of InterCity Rolling Stock Improvements. Prepared for British Railways Board. 
MVA (1985) Station Modernisation Priorities and Payoffs. Prepared for British Railways Board.

Navrud S. (2000) Economic benefits of a programme to reduce transportation and community noise - A contingent valuation study. Internoise 2000 The $29^{\text {th }}$ International Congress and Exhibition on Noise Control Engineering, 27-30 August 200, Nice, France.

Pommerehne W.W. (1988) Measuring the Environmental Benefits: A Comparison of Hedonic Technique and Contingent Valuation, in Bos D., Rose M. and Seidl C. (eds) Welfare and Efficiency in Public Economics Springer-Verlag, Berlin.

Timmermans, H. (1993) The Impact of Task Complexity on Information in MultiAttribute Decision Making. Journal of Behavioural Decision Making 6, 95-111.

Thune-Larsen H. (1995) Flystøyavgifter basert på betalingsvillighet, TOI report 289/1995. (English language summary report: Charges on Air Traffic Noise by Means of Conjoint Analysis).

Wardman M. and Bristow A.L (2004) Noise and Air Quality Valuations: Evidence from stated preference residential choice models, Transportation Research $D, 9(1)$ 127.

Widlert, S. (1998) Stated Preference Studies: The Design Affects the Results. in Ortuzar, J. de Dios. Hensher D. and Jara-Diaz S. (eds), Travel Behavior Research: Updating the state of play, chapter 7, 105-123, Pergamon, UK. 
Table 1: Flight Events per Hour by Time of Day: Summer 2002

\begin{tabular}{|l|r|r|r|}
\hline Time/Day & Manchester & Lyon & Bucharest \\
\hline Weekday 6am-9am & 20 & 12 & 2 \\
\hline Weekday 9am-6pm & 15 & 8 & 3 \\
\hline Weekday 6pm-10pm & 12 & 12 & 2 \\
\hline Saturday 6am-9am & 20 & 10 & 2 \\
\hline Saturday 9am-6pm & 15 & 6 & 3 \\
\hline Saturday 6pm-10pm & 12 & 5 & 2 \\
\hline Sunday & 15 & 6 & 3 \\
\hline Night & 2 & 1 & 1 \\
\hline
\end{tabular}


Table 2: Example WP Pairwise Choice

\begin{tabular}{|l|r|r|}
\hline & \multicolumn{2}{|c|}{ Time Period: Sunday 9am-6pm } \\
\cline { 2 - 3 } & A & B \\
\hline $\begin{array}{l}\text { Jumbo jets/large } \\
\text { engine planes }\end{array}$ & 1 per hour & 2 per hour \\
\hline $\begin{array}{l}\text { Two engine jets (eg, } \\
737, \text { Airbus) }\end{array}$ & 1 per hour & 2 per hour \\
\hline $\begin{array}{l}\text { Turbo-prop } \\
\text { (propeller) planes }\end{array}$ & 22 per hour & 34 per hour \\
\hline Total Flights & $£ 2$ more & $£ 5$ less \\
\hline Weekly council tax & A & B \\
\hline I would choose .... & & 30 per hour \\
\hline
\end{tabular}


Table 3: Possible BP Pairwise Choice

\begin{tabular}{|l|r|r|}
\hline & A & B \\
\hline Every Weekday 6-9am & 20 per hour & 30 per hour \\
\hline $\begin{array}{l}\text { Every Weekday 9am- } \\
\text { 6pm }\end{array}$ & 15 per hour & 10 per hour \\
\hline $\begin{array}{l}\text { Every Weekday 6- } \\
\text { 10pm }\end{array}$ & 12 per hour & 20 per hour \\
\hline Saturday 6-9am & 15 per hour & 20 per hour \\
\hline Saturday 9am-6pm & 20 per hour & 30 per hour \\
\hline Saturday 6-10pm & 20 per hour & 5 per hour \\
\hline Sunday 9am-6pm & 15 per hour & 30 per hour \\
\hline Every Night & 3 per hour & 1 per hour \\
\hline Weekly council tax & $£ 1$ more & $£ 4$ less \\
\hline I would choose .... & \multicolumn{1}{|c|}{ B } \\
\hline
\end{tabular}


Table 4: Example of BP Exercise Used - Manchester (Planes Per Hour)

\begin{tabular}{|l|l|l|l|l|l|l|l|}
\hline & \multicolumn{4}{|l}{ Deteriorations } & Current & \multicolumn{3}{l|}{ Improvements } \\
\hline Every Weekday 6-9am & 60 & 40 & 30 & 20 & 15 & 12 & 10 \\
\hline Every Weekday 9am-6pm & 40 & 30 & 20 & 15 & 12 & 10 & 6 \\
\hline Every Weekday 6-10pm & 30 & 20 & 15 & 12 & 10 & 6 & 4 \\
\hline Saturday 6-9am & 60 & 40 & 30 & 20 & 15 & 12 & 10 \\
\hline Saturday 9am-6pm & 40 & 30 & 20 & 15 & 12 & 10 & 6 \\
\hline Saturday 6-10pm & 30 & 20 & 15 & 12 & 10 & 6 & 4 \\
\hline Sunday 9am-6pm & 40 & 30 & 20 & 15 & 12 & 10 & 6 \\
\hline Every Night & 6 & 4 & 3 & 2 & 1 & \multicolumn{5}{|l|}{0} \\
\hline Weekly Tax & $+£ 10$ & $+£ 5$ & $+£ 2$ & 0 & $-£ 2$ & $-£ 5$ & $-£ 10$ \\
\hline
\end{tabular}


Table 5: Results of WP Models

\begin{tabular}{|c|c|c|c|c|c|c|}
\hline & \multicolumn{2}{|l|}{ Manchester } & \multicolumn{2}{|l|}{ Lyon } & \multicolumn{2}{|l|}{ Bucharest } \\
\hline & Coeffs $(\mathrm{t})$ & Values $(\mathrm{t})$ & Coeffs $(\mathrm{t})$ & Values $(\mathrm{t})$ & Coeffs (t) & Values $(\mathrm{t})$ \\
\hline Constant-Quieter & - & & $1.2850(7.6)$ & & $-1.2120(8.9)$ & \\
\hline Flights - Weekday 6am-9am & - & - & $-0.0711(4.9)$ & $1.39(4.0)$ & $-0.0903(5.7)$ & $0.28(2.7)$ \\
\hline Flights - Weekday 9am- 6pm & $-0.0294(2.4)$ & $0.52(2.4)$ & $-0.0412(5.2)$ & $0.81(4.1)$ & $-0.0987(5.1)$ & $0.31(2.7)$ \\
\hline Flights - Weekday 6pm-10pm & $-0.0698(5.5)$ & $1.24(5.1)$ & $-0.0878(5.3)$ & $1.72(4.1)$ & $-0.0865(4.7)$ & $0.27(2.6)$ \\
\hline Flights - Saturday 6am-9am & - & - & - & - & $-0.1064(6.1)$ & $0.33(2.7)$ \\
\hline Flights - Saturday 9am-6pm & $-0.0733(6.3)$ & $1.31(5.6)$ & $-0.0334(2.5)$ & $0.65(2.5)$ & - & - \\
\hline Flights - Saturday $6 \mathrm{pm}-10 \mathrm{pm}$ & - & - & $-0.0498(3.2)$ & $0.98(3.0)$ & - & - \\
\hline Flights - Sunday & $-0.0903(5.8)$ & $1.61(5.3)$ & $-0.0284(2.0)$ & $0.56(2.0)$ & $-0.0921(5.2)$ & $0.29(2.6)$ \\
\hline Flight - Night & $-0.1960(4.8)$ & $3.49(4.6)$ & $-0.0874(1.9)$ & $1.71(1.9)$ & $-0.1025(2.9)$ & $0.32(2.3)$ \\
\hline Weekly Tax (€) & $-0.0561(8.6)$ & & $-0.0510(4.8)$ & & $-0.3203(2.7)$ & \\
\hline$\rho^{2}$ & \multicolumn{2}{|l|}{0.070} & \multicolumn{2}{|l|}{0.059} & \multicolumn{2}{|l|}{0.032} \\
\hline Observations & \multicolumn{2}{|l|}{1545} & \multicolumn{2}{|l|}{1647} & \multicolumn{2}{|l|}{1895} \\
\hline
\end{tabular}


Table 6: Results of BP Models

\begin{tabular}{|c|c|c|c|c|c|c|}
\hline & \multicolumn{2}{|l|}{ Manchester } & \multicolumn{2}{|l|}{ Lyon } & \multicolumn{2}{|l|}{ Bucharest } \\
\hline & Coeff $(\mathrm{t})$ & Value $(\mathrm{t})$ & Coeff $(\mathrm{t})$ & Value $(\mathrm{t})$ & Coeff $(\mathrm{t})$ & Value $(\mathrm{t})$ \\
\hline \multicolumn{7}{|l|}{ Improvements } \\
\hline Weekday 6-9am & $-0.111(3.9)$ & $1.31(3.7)$ & $-0.117(2.8)$ & $3.25(2.2)$ & $-0.081(1.9)$ & $0.25(1.7)$ \\
\hline Weekday 9am-6pm & $-0.137(3.9)$ & $1.61(4.0)$ & $-0.199(3.7)$ & $5.53(3.1)$ & $-0.069(1.3)$ & $0.21(1.2)$ \\
\hline Weekday 6-10pm & $-0.215(4.9)$ & $2.53(3.9)$ & $-0.186(6.1)$ & $5.17(5.4)$ & $-0.305(3.2)$ & $0.94(2.9)$ \\
\hline Saturday 6-9am & $-0.150(5.5)$ & $1.77(5.3)$ & $-0.366(7.0)$ & $10.17(5.9)$ & $-0.308(3.2)$ & $0.95(2.5)$ \\
\hline Saturday 9am-6pm & $-0.182(4.7)$ & $2.14(3.8)$ & $-0.466(7.6)$ & $12.94(6.2)$ & $-0.112(1.7)$ & $0.35(1.5)$ \\
\hline Saturday 6-10pm & $-0.171(3.8)$ & $2.01(3.5)$ & $-0.676(6.6)$ & $18.78(5.8)$ & $-0.305(2.7)$ & $0.94(2.4)$ \\
\hline Sunday & $-0.174(4.3)$ & $2.05(4.1)$ & $-0.571(8.0)$ & $15.86(6.9)$ & $-0.098(1.4)$ & $0.30(1.3)$ \\
\hline Night & $-0.268(1.8)$ & $3.15(1.7)$ & $-1.068(2.5)$ & $29.67(2.1)$ & $-0.354(1.9)$ & $1.10(1.7)$ \\
\hline Weekly Tax (€) & $-0.085(3.2)$ & & $-0.036(2.1)$ & & $-0.323(2.0)$ & \\
\hline$\rho^{2} /$ individuals & 0.102 & 63 & 0.107 & 50 & 0.073 & 226 \\
\hline \multicolumn{7}{|l|}{ Deteriorations } \\
\hline Weekday 6-9am & $-0.047(4.2)$ & $0.31(4.1)$ & $-0.067(3.3)$ & $0.89(2.9)$ & $-0.107(9.8)$ & $0.04(8.5)$ \\
\hline Weekday 9am-6pm & $-0.051(3.5)$ & $0.33(3.4)$ & $-0.024(1.2)$ & $0.32(0.9)$ & $-0.100(9.9)$ & $0.04(8.3)$ \\
\hline Weekday 6-10pm & $-0.079(3.7)$ & $0.51(3.8)$ & $-0.046(2.5)$ & $0.61(2.2)$ & $-0.092(8.2)$ & $0.04(7.6)$ \\
\hline Saturday 6-9am & $-0.040(3.6)$ & $0.26(3.7)$ & $-0.069(5.9)$ & $0.92(4.3)$ & $-0.092(7.3)$ & $0.04(6.9)$ \\
\hline Saturday 9am-6pm & $-0.051(3.1)$ & $0.33(3.1)$ & $-0.067(3.4)$ & $0.89(2.9)$ & $-0.101(8.5)$ & $0.04(8.3)$ \\
\hline Saturday 6-10pm & $-0.049(2.4)$ & $0.32(2.5)$ & $-0.076(3.6)$ & $1.01(3.0)$ & $-0.104(8.1)$ & $0.04(7.9)$ \\
\hline Sunday & $-0.045(2.6)$ & $0.29(2.5)$ & $-0.113(7.2)$ & $1.51(4.0)$ & $-0.135(10.6)$ & $0.05(9.5)$ \\
\hline Night & $-0.290(3.0)$ & $1.88(2.9)$ & $-0.727(8.5)$ & $9.69(7.1)$ & $-0.424(12.9)$ & $\begin{array}{l}0.16 \\
(12.2)\end{array}$ \\
\hline Weekly Tax (€) & $-0.154(5.5)$ & & $-0.075(3.8)$ & & $-2.590(17.3)$ & \\
\hline$\rho^{2} /$ individuals & 0.134 & 63 & 0.093 & 50 & 0.102 & 225 \\
\hline
\end{tabular}


Table 7: Relative Valuations by Time Periods in WP and BP Models

\begin{tabular}{|l|c|l|l|l|l|l|l|l|l|l|l|l|}
\hline Period & \multicolumn{4}{|c|}{ Manchester } & \multicolumn{4}{c|}{ Lyon } & \multicolumn{3}{c|}{ Bucharest } \\
\hline & WP & $\begin{array}{l}\text { BP } \\
\text { Imp }\end{array}$ & $\begin{array}{l}\text { BP } \\
\text { Det }\end{array}$ & $\begin{array}{l}\text { BP } \\
\text { Avg }\end{array}$ & WP & $\begin{array}{l}\text { BP } \\
\text { Imp }\end{array}$ & $\begin{array}{l}\text { BP } \\
\text { Det }\end{array}$ & $\begin{array}{l}\text { BP } \\
\text { Avg }\end{array}$ & WP & $\begin{array}{l}\text { BP } \\
\text { Imp }\end{array}$ & $\begin{array}{l}\text { BP } \\
\text { Det }\end{array}$ & $\begin{array}{l}\text { BP } \\
\text { Avg }\end{array}$ \\
\hline Weekday 6-9am & - & - & - & - & 17.8 & 3.5 & 6.0 & 4.8 & 15.6 & 6.7 & 10.8 & 8.7 \\
\hline Weekday 9am-6pm & 6.4 & 14.0 & 9.9 & 12.0 & 10.3 & 6.1 & 2.1 & 4.1 & 17.2 & 5.6 & 10.8 & 8.2 \\
\hline Weekday 6-10pm & 15.2 & 22.0 & 15.2 & 18.6 & 22.0 & 5.7 & 4.1 & 4.9 & 15.0 & 25.1 & 10.8 & 18.0 \\
\hline Saturday 6-9am & - & - & - & & - & - & - & - & 18.3 & 25.3 & 10.8 & 18.1 \\
\hline Saturday 9am-6pm & 16.0 & 18.6 & 9.9 & 14.3 & 8.3 & 14.2 & 6.0 & 10.1 & - & - & - & - \\
\hline Saturday 6-10pm & - & - & - & - & 12.5 & 20.6 & 6.8 & 13.7 & - & - & - & - \\
\hline Sunday & 19.7 & 17.9 & 8.7 & 13.3 & 7.2 & 17.4 & 10.1 & 13.8 & 16.1 & 8.0 & 13.5 & 10.8 \\
\hline Night & 42.7 & 27.5 & 56.3 & 41.9 & 21.9 & 32.5 & 64.9 & 48.7 & 17.8 & 29.3 & 43.3 & 36.3 \\
\hline
\end{tabular}


Table 8: Overall Valuations ( $€$ per week) Implied by BP and WP Models

\begin{tabular}{|l|r|r|r|}
\hline SP & Manchester & Lyon & Bucharest \\
\hline BP - Imp & 11.48 & 91.20 & 3.75 \\
\hline BP - Det & 3.34 & 14.92 & 0.37 \\
\hline BP - Mean & 7.41 & 53.06 & 2.06 \\
\hline WP & 8.17 & 7.82 & 1.80 \\
\hline
\end{tabular}

Note: BP values are for those time periods for which a WP value is reported. 